\title{
Erratum to: Effects of a nurse-led medication self-management programme in cancer patients: protocol for a mixed- method randomised controlled trial
}

Hiroko Komatsu ${ }^{1 *}$, Kaori Yagasaki ${ }^{1}$ and Takuhiro Yamaguchi ${ }^{2}$

\section{Erratum}

Upon publication, the below errors were noticed in the original version of the article [1].

1) In the title of the article, 'randomised' should be spelt 'randomized'

2) i) In Table 2, 'MMAS-8' should instead read 'cMMAS-8'

ii) In Table 2, the following sentence should be included as a footnote: "Use of the cMMAS is protected by US copyright laws. Permission for use is required. A license agreement is available from: Donald E. Morisky, ScD, ScM, MSPH, Professor, Department of Community Health Sciences, UCLA School of Public Health, 650 Charles E. Young Drive South, Los Angeles, CA 90095-1772."

iii) In Table 2, there should be check marks under the 'Baseline,' 2 months', and ' 3 months' columns in the PDF as per the HTML

3) In the Acknowledgements, the following sentence should be included as the second paragraph: "Use of the cMMAS is protected by US copyright laws. Permission for use is required. A license agreement is available from: Donald E. Morisky, ScD, ScM, MSPH, Professor, Department of Community Health Sciences, UCLA School of Public Health, 650 Charles E. Young Drive South, Los Angeles, CA 90095-1772."

4) In citation 42, 'Morisky DE, Green LW, Levine DM. Concurrent and Predictive Validity of a Self-Reported Measure of Medication Adherence and Long-Term Predictive Validity of Blood
Pressure Control. Med Care. 196:24:67-74' should read:

A. Morisky DE, Ang A, Krousel-Wood M, Ward H. Predictive Validity of a Medication Adherence Measure for Hypertension Control. Journal of Clinical Hypertension 2008; 10(5):348-354.

B. Krousel-Wood MA, Islam T, Webber LS, Re RS, Morisky DE, Muntner P. New Medication Adherence Scale Versus Pharmacy Fill Rates in Seniors With Hypertension. Am J Manag Care 2009; 15(1):59-66.

C. Morisky DE, DiMatteo MR. Improving the measurement of self-reported medication nonadherence: Final response. J Clin Epidemio 2011; 64:258-263. PMID: 21144706

\section{Author details}

${ }^{1}$ Faculty of Nursing and Medical Care, Keio University, 35 Shinanomachi, Shinjuku-ku, Tokyo 160-8582, Japan. ${ }^{2}$ Division of Biostatistics, Tohoku University Graduate School of Medicine, 1-1 Seiryo-machi, Aoba-ku, Sendai, Miyagi 980-8574, Japan.

Received: 5 October 2016 Accepted: 5 October 2016 Published online: 24 October 2016

\section{Reference}

1. Komatsu H, Yagasaki K, Yamaguchi T. Effects of a nurse-led medication selfmanagement programme in cancer patients: protocol for a mixed-method randomised controlled trial. BMC Nursing. 2016;15:9. doi:10.1186/s12912016-0130-1.

* Correspondence: hkomatsu@sfc.keio.ac.jp

${ }^{1}$ Faculty of Nursing and Medical Care, Keio University, 35 Shinanomachi, Shinjuku-ku, Tokyo 160-8582, Japan

(c) The Author(s). 2016 Open Access This article is distributed under the terms of the Creative Commons Attribution 4.0 International License (http://creativecommons.org/licenses/by/4.0/), which permits unrestricted use, distribution, and reproduction in any medium, provided you give appropriate credit to the original author(s) and the source, provide a link to the Creative Commons license, and indicate if changes were made. The Creative Commons Public Domain Dedication waiver (http://creativecommons.org/publicdomain/zero/1.0/) applies to the data made available in this article, unless otherwise stated. 
Table 2 Measures and Timings for Measurements

\begin{tabular}{|c|c|c|c|c|}
\hline Measure & Questionnaire & Baseline & 2 months & 3 months \\
\hline Demographics & Patient Questionnaire & $\circ$ & & \\
\hline \multirow[t]{2}{*}{ Medication adherence } & MPS & $\circ$ & $\circ$ & $\circ$ \\
\hline & CMMAS-8 & $\circ$ & $\circ$ & $\circ$ \\
\hline Self-efficacy & GSE & $\circ$ & $\circ$ & $\circ$ \\
\hline $\mathrm{QOL}$ & FACT-B & $\circ$ & $\circ$ & $\circ$ \\
\hline Psychological distress & K6 & $\circ$ & $\circ$ & $\circ$ \\
\hline Symptom severity/interference & MD Anderson Symptoms Inventory & $\circ$ & $\circ$ & $\circ$ \\
\hline
\end{tabular}

